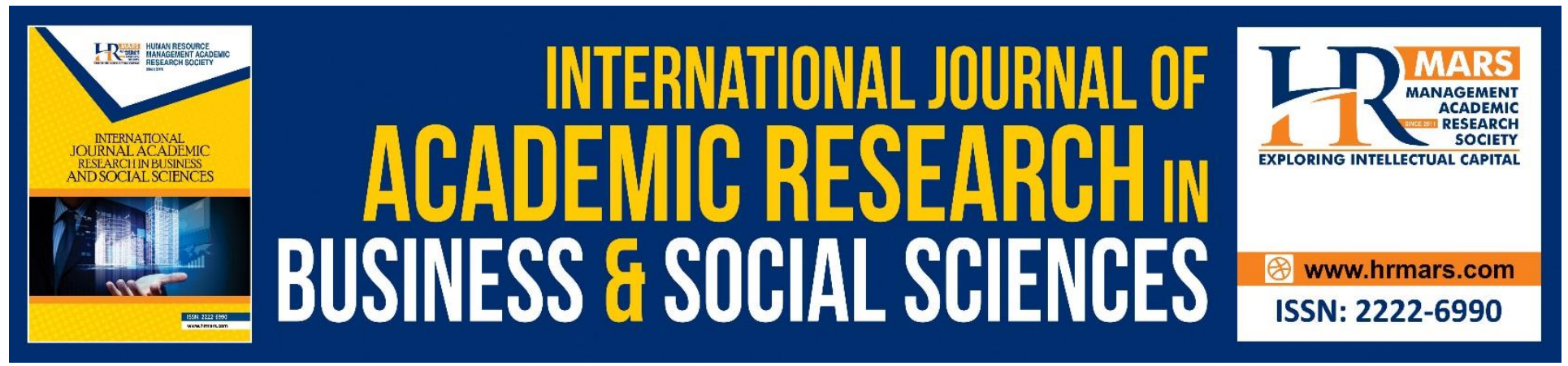

\title{
Developing Employability Skills from Service-learning Experience at Putra Future Classroom (PFC)
}

Muhd Khaizer Omar, Mas Nida Md Khambari, Aini Marina Ma'arof, Ismi Arif Ismail, Tengku Fadilah Tengku Kamalden, Habibah Ab. Jalil, Siti Suria Salim, Nur Aira Abd Rahim, Siti Noormi Alias, Mohd Hazwan Mohd Puad, Muhamad Mokhtar Muhamad, Mohd Mursyid Arshad

To Link this Article: http://dx.doi.org/10.6007/IJARBSS/v8-i12/5046

DOI: $10.6007 /$ IJARBSS/v8-i12/5046

Received: 28 Oct 2018, Revised: 08 Dec 2018, Accepted: 24 Dec 2018

Published Online: 27 Dec 2018

In-Text Citation: (Omar et al., 2018)

To Cite this Article: Omar, M. K., Khambari, M. N. M., Ma'arof, A. M., Ismail, I. A., Kamalden, T. F. T., Jalil, H. A., Arshad, M. M. (2018). Developing Employability Skills from Service-learning Experience at Putra Future Classroom (PFC). International Journal of Academic Research in Business and Social Sciences, 8(12), 472-490.

Copyright: (C) 2018 The Author(s)

Published by Human Resource Management Academic Research Society (www.hrmars.com)

This article is published under the Creative Commons Attribution (CC BY 4.0) license. Anyone may reproduce, distribute, translate and create derivative works of this article (for both commercial and non-commercial purposes), subject to full attribution to the original publication and authors. The full terms of this license may be seen

at: http://creativecommons.org/licences/by/4.0/legalcode

Vol. 8, No. 12, 2018, Pg. 472 - 490

http://hrmars.com/index.php/pages/detail/IJARBSS

JOURNAL HOMEPAGE

Full Terms \& Conditions of access and use can be found at http://hrmars.com/index.php/pages/detail/publication-ethics 


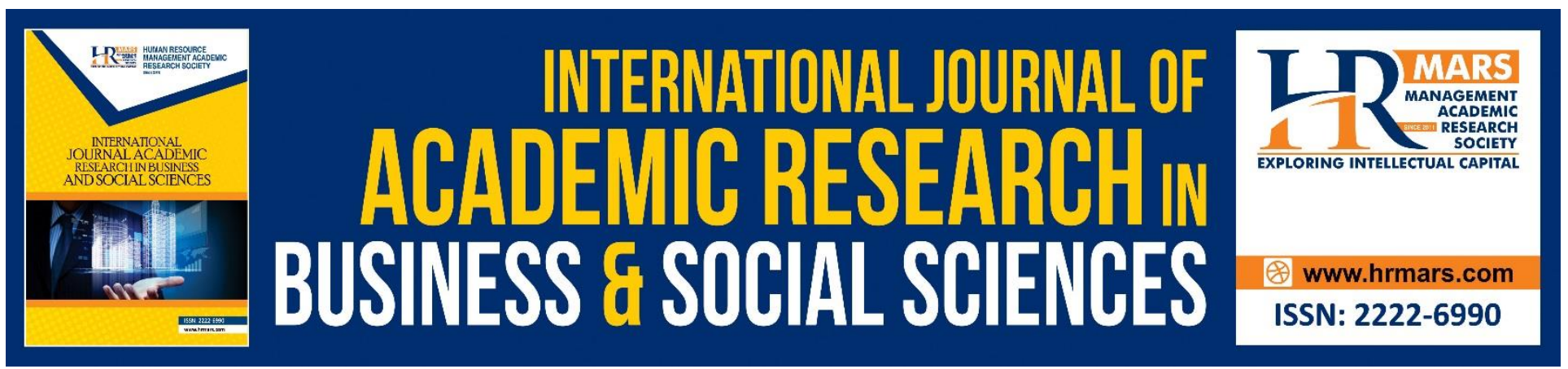

\title{
Developing Employability Skills from Service-learning Experience at Putra Future Classroom (PFC)
}

\author{
Muhd Khaizer Omar, Mas Nida Md Khambari, Aini Marina Ma'arof, \\ Ismi Arif Ismail, Tengku Fadilah Tengku Kamalden, Habibah Ab. \\ Jalil, Siti Suria Salim, Nur Aira Abd Rahim, Siti Noormi Alias, Mohd \\ Hazwan Mohd Puad, Muhamad Mokhtar Muhamad, Mohd Mursyid \\ Arshad
}

Faculty of Educational Studies, Universiti Putra Malaysia, 43400 UPM Serdang, Selangor Darul Ehsan, Malaysia

\begin{abstract}
Service-learning imposes a practical dissemination of knowledge though hands-on practices and 'learning-by-doing'. Often, service-learning has been misinterpreted with the concept of volunteerism where service-learning offer the application of theoretical knowledge which learned through traditional classroom then applying knowledge through volunteering work. The blending process of theoretical knowledge and practical learning environment produces meaningful learning experiences and tends to be more effective in remembering and skills-to work. We carried out a case study of 15 postgraduate students who experienced service-learning project at Putra Future Classroom at the Faculty of Educational Studies, Universiti Putra Malaysia. A specific project call "Earth Day" was organized in commemorating the annual earth day celebration around the world. The project involved a children age between four to six years old who experienced numerous activities related to earth day awareness campaign. This article explored narrative feedback through qualitative approach to discover postgraduate students' experiences of organizing service-learning project and explore the learning experiences from theoretical knowledge learned in the traditional classroom for the course Program Evaluation in Technical and Vocational Education and Training (TVE5006 and EDU5443). At the end of the service-learning project, the students were asked to answer an open-ended qualitative question disseminated via JotForm, an online questionnaire platform during the process of qualitative data collection. All answers were recorded and later analysed thematically using a two-layer of constant comparative analysis method and triangulated with class assignments, obervations and reflection notes. The findings indicated seven themes that emerged from the analysis. Salient benefits of service-learning project for post graduate learning
\end{abstract}


INTERNATIONAL JOURNAL OF ACADEMIC RESEARCH IN BUSINESS AND SOCIAL SCIENCES Vol. 8, No. 12, Dec, 2018, E-ISSN: 2222-6990 @ 2018 HRMARS

experiences to enhance their employability skills for the $21^{\text {st }}$ century skills before entering employment market were suggested.

Keywords: Volunteerism, Employability Skills, Community-Based Learning, Experiential Learning

\section{Introduction}

Emphases are given to the educational provider in ways teaching and learning environment to enrich student overall experience. Voracious amount information in theoretical form will be worthless if students failed to practice in naturalistic settings. Often, the disparity of transferring knowledge from classroom to practical become hurdles to some graduates because they face difficulties to understand the nature of the job. In fact, some graduates experience minimum exposure to industry settings although they work within the same specialization when they earn their bachelor degree. Therefore, service-learning primarily build upon students experiential learning, career-based education, and school to work program was the primer for this teaching approach (Shumer, 2014). The service learning prosper the overarching experience transferring theoretical knowledge to practicality to compliment both learning practices to reach maturation in knowledge paradigm.

Undeniably, service-learning has been widely acknowledged in the educational settings worldwide. According to Kuh (2008), service-learning is one of the top ten teaching approaches within the higher education systems in the United States. In general, the basis of service-learning combines two aspects into the teaching and learning environment: knowledge-based content and values related to community service task and engagement (Berasategi, Alonso, \& Roman, 2016), has proven to be an effective $21^{\text {st }}$ century teaching methodology. Fundamentally, the premise of service learning is to integrate community services into academic content (Furco, 2001), deliver theoretical knowledge and create practical experience to enhance students' learning experience. As a matter of fact, researchers have studied the effects of service-learning in learning environment (see Folgueiras, Luna \& Puig, 2013; Gezuraga \& Malik, 2015; Smiley et al., 2012) and confirmed that service-learning helps students to foster civic responsibility, social skills and a positive personality. Consequently, this indirectly increases students' confidence and exposes students to the critical thinking culture to achieve deeper understanding of the knowledge content. The introduction of this new teaching methodology is vital as students nowadays are inundated with curriculum which heavily emphasise on theoretical knowledge and book-based learning. Thus, the current learning environment is boring and repetitive.

Although the service learning definition can be interchangeably regarded to research and project contextual approaches, the primary understanding lies to complimentary and transferring knowledge learned in the classroom to practical or hands-on skills to employment. The consensus has been made among scholars, evaluators, and practitioners on the subtle definition on service learning. For example, Billig and Waterman (2014) mentioned the service-learning project greatly along the mutual relationship and bond within communities to facilitate the transfer of knowledge and skill application. It is also agreed upon the context of service-learning must benefit both parties in which transformation of knowledge, values, and attitudes towards enhancing the human capital progression. Also, the process of service-learning also sequentially undergone thorough systematic 
INTERNATIONAL JOURNAL OF ACADEMIC RESEARCH IN BUSINESS AND SOCIAL SCIENCES Vol. 8, No. 12, Dec, 2018, E-ISSN: 2222-6990 @ 2018 HRMARS

planning, action, reflection, and celebration (Billig \& Waterman, 2014) as this will become characterization of the relationship between service-provider and the recipients of the program.

Service-learning is a powerful tool to engage students within group and organization in terms of building an early rapport and networking. A resourceful practitioner in industry, who possess experiential industrial environment are the best guidance for students to understand the real nature of workforce employment. Although students come with diverse educational background, this socially environment benefit students to engage with potential industry for their future employment. Following a number of social skills, which is one of the accumulations of the $21^{\text {st }}$ century skills traits required student to inculcate a civic responsibility with an objective to develop grassroots who practice responsibility and cognizance of surrounding, which is defined as transformative experiential education (Huda et al., 2018). The situation indicates that service-learning can offer a connectivity between higher educational providers and community in terms of different aspects of knowledge transfer for example research, internship training and educational programs. The overall experience definitely will encounter the dyssynchronization of what the university can offer and what industries really needs from potential employees among the fresh graduates.

One of the most interesting features of service-learning is instructors and lecturers are utilizing classroom environment into a fieldwork for students to experience the real environment of workplace. With the possibility of engaging learners and community in the classroom, stakeholders will experience the learning environment that cater both parties' requirement and knowledge seeking of certain interest and topics. Howard (2014) added upon this argument that the concept of laboratory of experimenting the communities as participant in the service-learning project successfully accommodate the loopholes in the curriculum and strengthening student's citizenship preparation in venturing the future life settings. This will ultimately assist students in solving individual and community-wide resource and advocacy problems (Howard, 2014). Part of the service, students are immersed within the experienced in which quite differently from the standard classroom as a function of seeing its application in ways that make a difference in the lives of others (Waterman, 2014).

This article primarily explored the impact of the service-learning from postgrad courses taught which previously taught in traditional classroom and as depicted monotonous. The postgraduate students delve into naturalistic settings of service-learning project that was created by them in terms of course content and tentative schedule. Students have been briefed about the clear distinction between service learning and volunteerism by connecting their course objectives to the service being provided. The process was adapted from McDonald and Dominguez (2015) research outcomes on strategizing service-learning project. The students went through develop a framework for planning, assessment, and reflection stage to investigate the impact of service-learning for their overall experience enrolling in the course. A successful partnership with the Family, Adolescent and Child Research Centre of Excellence (FACE), Universiti Putra Malaysia to ensure the service-learning successful. Clearly defining the community in this case referring to the kids in between four to six years old setting to be used for the service-learning project will ensure a more positive outcome from the program theme 
INTERNATIONAL JOURNAL OF ACADEMIC RESEARCH IN BUSINESS AND SOCIAL SCIENCES

Vol. 8, No. 12, Dec, 2018, E-ISSN: 2222-6990 @ 2018 HRMARS

selected which is Earth Day. Developing the partnership framework through purposeful communication with all partners is the key to successful service-learning projects.

\section{Service-Learning as an Alternative Teaching and Learning Approach}

This section explores contemporary studies on service-learning from different perspectives from scholars. It appears from the aforementioned investigation that most attention has been to volunteerism, as described by Henderson (1984), premise of volunteerism is closely related to activities which are non-monetary oriented and supported by individuals who have time and energy, depicted a distinction with service-learning context. Service-learning, on the other hand, promotes a wide expansion of humanitarian efforts with the systematic process of embedding knowledge content into practical work in a way of serving the community.

Attention has been paid on community-based project that includes volunteerism and servicelearning, at different level of educational environments that includes schools, colleges, and universities (Dienhart et al., 2016; Richard, Keen, Hatcher, \& Pease, 2017). The norm of communitybased project has always been placed as credit hour in some of the university program to encourage students participate in such activities. The world of employment with diverse fields, yet required graduates to be partaken with community bases project to enhance their employability skills and networking. In particular, the whole community, the administration and teachers implement networking with a mission to develop student interpersonal skills that include professionalism and employability skills (Berasategi, Alonso, \& Roman, 2016). One task this secured job will have to contend with the challenge in placing themselves is employment because even today the unemployment rate can be disastrous and eventually depriving the prospect of nation for human capital well-being and the stability of national economic.

The effect of service-learning has been studied over the years because of its proven to successfully developed positive student behaviours and the spirit of the citizenship. Service-learning was found to have a positive association with students' citizenship/civic behaviours, both in- and out-of-class (Furco, Jones-White, Huesman, \& Gorny, 2016; Richard, Keen, Hatcher, \& Pease, 2017). Servicelearning provides a rich learning environment for civic outcomes after college. It provides opportunities for both formal and informal reflections and conversations with others. These conversations occur with peers, faculty, community members, or community site supervisors, and may involve dialogue across difference. These conversations, both formal and informal, may promote moral and cognitive reflection at service sites, in the classroom, and in informal discussion settings on campus or in the van going to or returning from service sites (Richard, Keen, Hatcher, \& Pease, 2017). This entire process promotes curiosity and care for the surrounding community which increases the citizenship and belongingness.

Service-learning has proven to become the platform of promoting responsibility, caring, citizenship, competence, and a practical knowledge to communities, nations and global (Waterman, 2014). The benefits of service-learning flourishes dissimilar type of learning environment that could prosper the talents of learners to the highest potential. In addition to that, the responsibility towards people and 
community has been translated to the meaningful experienced from the community service-based project as projected from service-learning activities. With a mixture if innate beliefs and developed civic responsibility and accumbent knowledge also experienced while engaging in service-learning project, the graduates now have holistic and positive moral, values, and attitudes to become effective and competent grassroot for the future.

Researchers have studied the effect of service-learning in a different multicultural perspectives (Furco, Jones-White, Huesman, \& Gorny, 2016; Kohlbry, 2016; Sun \& Yang, 2015). As service-learning project offers a wide exposure to a different cultural settings, the immersion of different understanding of what different culture practices and beliefs system promotes better understanding of diversity of the people around the globe. For example, Furco, Jones-White, Huesman, and Gorny (2016) mentions the significant positive direct relationships between servicelearning and student perceptions of sociocultural gains as well as between service-learning and students' civic-oriented behaviours (both in- and out-of-class). Broad perspectives of multiculturalism in a school environment have informed teachers of the need to mix with other cultures. This concept requires teachers' ability to understand and to resist the different cultural issues and contexts to prevent misunderstanding and misjudgment of others' belief systems. Bias of races, colors, and ethnicities must be diminished to give equality in shaping future generations to believe in the concept of diversity and intensity of collective society effort.

The broader the spectrum of students venturing the service-learning project, the better they understand different cultures and perspectives of such group of people. This is vital as working with boundaryless environment for example outsourcing manpower to different countries will help graduates to easily blend in with different cultures. Understanding of different ethnics' beliefs system was carried out Kolhbry (2016) on international service-learning immersion experiences to foster cultural competence among nursing students. Findings from participants demonstrated and articulated that these program experiences strengthen the process of becoming culturally competent. The research findings support the inclusion of international service-learning experiences with debriefing and reflective learning as effective teaching strategies asserts the entire outcome from the service-learning project. Noticeably, nursing as service-based career necessitate to undergone service-learning experience to encounter different ways of giving treatment also encourage nurses to be competent in understanding people who come from diverse religious beliefs, cultural perspectives, and ethnic practices.

The contradictory findings as to regards service-learning beneficial impacts from students experience is something worth to be discussed. Despite prior evidence, the results was contradicted to a study conducted by Dienhart et. al. (2016). For example, students were reported not to be interested in involving in the future community work although they have had a period of time venturing community service project at the university level. However, they referred more favouritism on service-learning project in which they took part. The findings suggest that students' motivations to participate in community-engaged activities are not shaped simply by whether or not community engagement is required in service-learning classes, however, also by other factors including how the 
INTERNATIONAL JOURNAL OF ACADEMIC RESEARCH IN BUSINESS AND SOCIAL SCIENCES Vol. 8, No. 12, Dec, 2018, E-ISSN: 2222-6990 @ 2018 HRMARS

engagement opportunity is contextualized, which is one of the constructs in service-learning framework.

The premise of service-learning activities reflects upon the engagement of service provider and the recipient. Few scholars agreed that service-learning is the best platform for a service-based career for example nurses (Curtin, Martins, \& Schwartz-Barcott, 2015; Foli, Braswell, Kirkpatrick, \& Lim, 2014) and educators that include teachers (Sun \& Yang, 2015; Zins, Bloodworth, Weissberg, \& Walberg, 2007). It is proven that service learning successfully exercises and increased empathy and ability to communicate effectively with patients from life situations very different from their own, especially in regards to nursing service (Curtin, Martins, \& Schwartz-Barcott, 2015). The communication skills that learned prior to employment flourishes experiences on how to become an effective employee in terms of giving the best service with clear instruction and treatment of certain situation for instance in medical care service. The approach to people is at best when the employee experienced earlier in the process of learning at educational institutions therefore they would not be awkward to carry out the task even though they are newcomer in the realm of the job.

Service-learning implores the pre-service teachers to promulgate the requirements for the effective language and communication efficiency as requisite for effective teacher. Sun and Yang (2015) studied on the relationship between service-learning and with oral communication training in English as a Foreign Language (EFL) speaking class and using Web 2.0 tools for example YouTube for video creation using English as medium of presentation and Facebook as platforms to connect with international students and peers. The service-learning project required students to engage with training with potential communities and program stakeholders. The results suggest that the project enhanced EFL students' public speaking-related skills (e.g., idea and content development, and pronunciation), built their confidence in speaking English, and allowed them to develop their own learning process and strategies (Sun \& Yang, 2015). The above finding is consistent with the study by Zins, Bloodworth, Weissberg, and Walberg (2007). They asserted that service learning is a productive way to utilize innovative instructional methodologies and engage students in the learning process, which entirely increase student's capability to interact and communicate with people in global perspectives.

The purpose of this review was to view the trends in service-learning studies within the past years and see impacts in contemporary analysis of scholars findings. It is clear from the research reviewed that service-learning is immersed and widely practiced throughout universities although the practical approaches of service-learning has been interchangeably define as community-based project, volunteerism, and internship. Along with this, it is also clear that the field of service-learning must compose with clear distinction that any project must undergone thorough theoretical knowledge which then transfer to practical effort. This argument of inquiry is very important as at its centre is a concern with helping students to grow and offer wide variety of meaningful learning experience. Helping students become better graduates with accumulation of knowledge and skills is also extremely important in employment and also in current society to embark the salient of citizenship role and human capital values. 
INTERNATIONAL JOURNAL OF ACADEMIC RESEARCH IN BUSINESS AND SOCIAL SCIENCES

Vol. 8, No. 12, Dec, 2018, E-ISSN: 2222-6990 @ 2018 HRMARS

\section{Theoretical Paradigm}

Service-learning is an educational pedagogy derived from experiential learning theory. This theory is influenced by John Dewey (1938) who proposed two principles namely i) the principle of continuity and ii) the principle of interaction. It was supported by Giles and Eyler (1994b) that the philosophy of Dewey is a legitimate source for developing theory of service-learning. The essence of servicelearning relies on a philosophy of service and learning that occurs in experience, reflection and civic engagement within collaborative relationship among community partners (Flecky \& Gitlow, 2011). Furthermore, this pedagogy gives the opportunities for participants to reflect on their activities within educational and community objectives. Howard and Jacoby (2015) agreed that reflection has become among the core elements of service-learning based on Dewey's proposition. Therefore, it is apparent that service and learning have to balance each other to create partnership experience.

One of service-learning's theoretical foundations is that from Kolb's Experiential Learning Model. This model comprises four elements; concrete experience, observation of reflection on that experience, formation and synthesis of abstract concepts based on the reflection and active experimentation that evaluates the concepts in new situations. Participants can enter the cycle at any point, but servicelearning is often designed to begin with concrete experience. These four elements form a cycle or spiral of learning as illustrated in Figure 1 below.

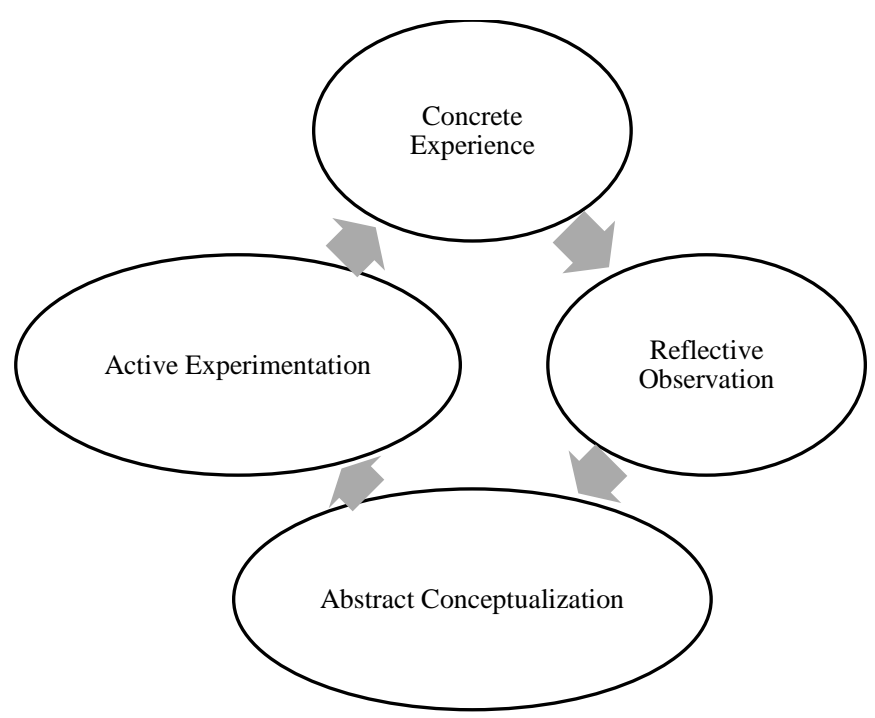

Fig (1) Experiential Learning Model, adapted from Kolb

Kolb (1984) stated that the process of learning starts with concrete experience as the learners test their newly developed concepts and continue with other elements. Jacoby (1996b) stated that service- learning is a form of experiential education in which students engage in activities that address human and community needs together with structured design to promote students' learning and development. In comparison, this is different than volunteerism and community service from explicit learning objectives with community interactions to meet the driven needs. It was encouraged by Furco (1996) that volunteerism only provides service with no intentional link to reflection and 
INTERNATIONAL JOURNAL OF ACADEMIC RESEARCH IN BUSINESS AND SOCIAL SCIENCES

Vol. 8, No. 12, Dec, 2018, E-ISSN: 2222-6990 @ 2018 HRMARS

learning while community service does not necessarily include reflection and may lack of academic content. Thus, the misconception on service- learning with other forms of programme will affect the participants' learning goal and community needs.

\section{Research Objective and Research Question}

The objective of this paper is to determine the impact of service-learning project to post-graduate students' program on developing their employability skills and to what extent service-learning improves students experiential learning by involving community and educational stakeholders. The contribution of the study is obvious as the resulting outcomes can be capitalized as guidelines to consider the application service-learning program in course structure and curriculum making. This will transfer the theory and content of the classes to creative and relevant problem-solving which is highly essential for today's workplace. Also, to strengthen and build the relationship between university and community in which both entities cold benefit from the creative energy of student service, while providing those students with work opportunities in the real-life environments. In order to fulfil the research objective, the study was carried out based upon the stated research question: What have the students learned after service-learning project?

\section{Methods}

A case study based on the qualitative approach was employed in this study. In this study, an event which happened within the community was examined and emerging themes which were influential in the prediction of the program's effectiveness were identified. This measure was taken, to elucidate the benefits of the program for future projection (Jacoby, 1996). Evidently, the postgraduate students who were involved in the service-learning project were primary resources for the data collection. Conversely, the secondary data were derived from the class assignments, obervations and reflection notes by students which were subsequently utilized for triangulation processes.

\section{Commemorating Earth Day: The Service-learning Project}

Earth Day at Putra Future Classroom has been conducted to inculcate the positive attitudes among the kids about preserving the nature. They have been exposed and taught about recycle. Recycling is actually an easy way for students to get involved in improving their local environment, and it is often promoted as extremely beneficial. In addition, recycling saves energy, reduces raw material extraction and combats climate change. The vast majority of studies have found that recycling our rubbish is better for the environment rather than incinerating or landfilling it. Therefore, the knowledge about recycle has become vital to children as it also seeks to provide knowledge to lessen or reverse the negative behaviours that lead to the degradation of the environment. Regarding to Porter (1997), children are of particular interest for environmental education because they are less likely to have formed harmful environmental behaviours that must be unlearned, and they have a longer period in which they are able to positively influence the environment. Furthermore, children can serve as agents to encourage others to act in an environmentally responsible manner which can be translated to practical behaviour of grassroots in such nations. 
The younger generation, especially today's students will face the world that faces many challenges such as environmental degradation on a scale never seen. They need to be provided with education that highlights world issues so that leadership and universal values can be nurtured. This can be done by inculcating the values that can be learned through daily life, which fosters civic behaviour as stated in Malaysia Education Blueprint 2013-2025: Preschool Pre-School to Post-Secondary Education (Blueprint, 2016). Fortifying environment-loving attitudes in the early stages of childhood can also increase the civic values of society as well as drive the development and well-being of Malaysia as a developing country.

In line with the celebration of Earth Day 2018, Putra Future Classroom, Faculty of Educational Studies with Family, Adolescent and Child Research Center of Excellence (FACE) collaboration, the Human Ecology Faculty has designed an interactive seminar aimed at inculcating the awareness of the young generation on the importance of preserving the environment, with a consistent theme of ending plastic pollution. Early awareness needs to be nurtured among the world's generations as early as six years as this generation is the leader of the future who will meet and protect the environment in the future.

Planning for this interactive seminar is one of the Putra Future Classroom initiatives to develop content that can be shared and tried by participants. Because Putra Future Classroom aims to be one of the edutech-tourism attractions under Putra EduPark, Earth Day's premier celebration at Putra Future Classroom is a pilot test for content test-run and simulation for packages to be served to guests who visit Putra Future Classroom in the future. This package is the first package developed to provide an authentic experience of using Putra Future Classroom to visitors. It is also a business of Putra Future Classroom to collaborate with the industry and the surrounding communities and support the Malaysia Education Blueprint 2013-2025.

\section{Data Collection}

In this study, a purposive sampling was carried out to determine the participants of the study. The population of this study was composed of postgraduate students from Masters of Education in Technical and Vocational Education program. Specifically, those students who enrolled in TVE5006/EDU5443, Program Evaluation in Technical and Vocational Education course from the Faculty of Educational Studies, Universiti Putra Malaysia (UPM). For the purpose of this study, a structured question was employed to the students using an online platform called 'JotForm' in a designated time and timeline. The structured service-learning project reflection question was adapted from Austin Community College District service-learning division which is accessible online. Simultaneously, the service-learning environment of the students was observed. During the observation, field notes were taken by the researchers to gain an initial understanding of how servicelearning can enhance experiential learning of students being carried out through the job scope.

Particularly, samples of students who enrolled in this course was selected with regards to their basic pedagogical knowledge acquired from educational-based courses taken at the faculty. Precisely, a total of 15 students were requested to participate in the planning of the service-learning project with 
INTERNATIONAL JOURNAL OF ACADEMIC RESEARCH IN BUSINESS AND SOCIAL SCIENCES

Vol. 8, No. 12, Dec, 2018, E-ISSN: 2222-6990 C 2018 HRMARS

other two courses handled by different researchers. For the purpose of this project, the students were required to develop a program (for three slots with different timeline) based on the Earth Day to ensure the service-learning project fulfils the objective of the program

Based on this service-learning project, a one-day program was conducted with the children ages from four to six years old from the Family, Adolescent and Child Research Centre of Excellence (FACE), Universiti Putra Malaysia. Notably, the module was developed and utilized as the main servicelearning content prior to the event. The program took place on April 20, 2018 (Friday) at Putra Future Classroom (PFC) and PFC Lounge, UPM involving 60 people (30 preschool children and escort teachers, 25 postgraduate students of EDU5304 Instructional Media, TVE5006/EDU5443 Program Evaluation in Technical and Vocational Education and EPY5009 Thinking and Reasoning10 lecturers and technical staff of PFC and Infocomm Development Centre iDEC). The table 1 described the tentative and activity:

Table 1. Tenative of the Earth Day Program

\begin{tabular}{|c|c|}
\hline Time & Activity \\
\hline 09:30 a.m. - 9:45 a.m. & Registration \\
\hline 9:45 a.m. & Earth Day@PFC start \\
\hline 9:45 a.m. - 9:55 a.m. & Introduction to Earth Day \\
\hline \multirow[t]{5}{*}{ 9:55 a.m. - 10:35 a.m. } & Stations \\
\hline & $\begin{array}{l}\text { A. Recycleable/non-recycleable things } \\
\text { (Card Games \& ClassDojo) } \\
\text { B. TuTu the Sea Turtle } \\
\text { (Storytelling with AR popup scrapbook \& } \\
\text { Hologram) }\end{array}$ \\
\hline & $\begin{array}{l}\text { C. Effects of plastic pollution on Earth and } \\
\text { marine animals } \\
\text { (3D Earth \& AR embedded Globe) }\end{array}$ \\
\hline & D. The Plastic Journey \\
\hline & (AR, Hologram \& 3D Model) \\
\hline 10:35 a.m. - 10:55 a.m. & $\begin{array}{l}\text { Clean Walk Role Play } \\
\text { (recycleable things sorting games) }\end{array}$ \\
\hline 10:55 a.m. $-11: 10$ a.m. & $\begin{array}{l}\text { Upcycle Gallery with QR Codes } \\
\text { (upcycled products from reusable and } \\
\text { recycleable things) }\end{array}$ \\
\hline 11:10 a.m. $-11: 30$ a.m. & $\begin{array}{l}\text { Shark \& Ball Game } \\
\text { (Shark crafting with plastic bottles) }\end{array}$ \\
\hline 11:30 a.m. $-12: 00$ p.m. & $\begin{array}{l}\text { Certificate and photo sessions with Dean of } \\
\text { the Faculty of Educational Studies \& }\end{array}$ \\
\hline & Dean of the Faculty of Human Ecology \\
\hline 12:30 p.m. & Lunch and Close \\
\hline
\end{tabular}




\section{Results and Findings}

The thematic analysis was utilized, specifically a constant comparative analysis to explore the emergence themes from structured questions distributed using online platform. A two-layer of color coding analysis, started with the use of 'WordCloud' to determine the most highlighted words described in the narrative. The words depicted from the 'WordCloud' were then undergone a comparative analysis using Excel and were colored coded upon the emergence words that contributed to meaning-making of the statement. The themes that emerged from the analysis were triangulated from the observation and field notes that were taken prior to the online form distribution. From the analysis, we came across seven different skills emerged from the successfully service-learning project. These seven skills were communication, problem-solving, social and intercultural, team work and cooperative, positive attitude, decision making, and agent of change. We then compared with the $21^{\text {st }}$ century learning skills in the discussion section to explore the service-learning project outcome.

\section{The Nurturing Process of Employability Skills}

To start with, service-learning has proven to become a platform of student skills for employment. Because the nature of service-learning is to delve in with naturalistic of job environment, servicelearning brings essential elements of what the reality exists outside from the classroom settings. For example, participant valued the service-learning experience as to develop their communications skills. Informant (3) talked about his overall experience, "for me, I learned about communication is one of the most important professional skills you can develop...... The process of seeking an the work experience itself, and reflecting afterward, will all contribute to the growth of your communication skills. The participant reflected his salient notion and regards the service-learning project compliment the work experience that become so important to have good communication skills. In addition to that, participant also was trained to become a public speaker. Although it was coerce in the first place, but the informant (14) shared his notion about the outcome from his experience, "Technically I found that I can speak in front of a lot of people. I just need sometimes to adjust myself to the surrounding". Under duress, the participant successfully manage to become effective speaker and this applies to both languages, native and English.

On top of that, service-learning project promotes creative and critical thinking via the practice of problem solving skills. Informant (6) espoused her experience in navigating solution towards issue pertaining the earth day project as, "some problem that exist while conducting problem teach me to be creative to solve the problem, mostly when handling the kids. On another note, participants were engaged with kids as early as four-years old and understanding kids for those who never experienced dealing with kids intrigue consciousness of myriad issues especially in terms of behaviour and giving instruction to the kids. This scenario promotes different environments especially those who have never encountered kids as their client. The same informant (6) also suggested that "next, when problem comes, we need to always be positive and try to solve it calmly" depicted her characterization when it comes to solution of problem during the project. 
The service-learning project was regarded as successful event if participants could venture new perspectives in understanding human beings from diverse backgrounds and be sociable. For example, informant (1) experienced different cultural understandings because she worked with classmate from different country and immerse with environment that promotes different understanding and values towards others. She espoused that, "I can work with the team member who are from different countries and we have a good outcome for this programme. On another note, informant (6) and (14) relatively stated, "when I get involved and serve in these program I am automatically subjected to being part of the community. This allows me to meet and learn from a range of new people and create memorable experience with others that will last a lifetime and "to work with people with different background, I need to prepare for social skills. Different people has different personality that I need to deal with". Both situations highlight the possibilities of the future workforce that entirely have been imposed to boundaryless working environment and immerse with different types of people. We have seen that people work abroad and also work remotely from home or migrate to different countries. Service-learning projected the possibility of having intercultural raining and learn to accept others worldviews about something related to cultural beliefs, religious understandings, and ethnicities practices.

In the process of understanding how teamwork can produce meaningful relationship of team members, service-learning project enhances collaborative and cooperative learning engagement among participants starting from the planning stage to the event-day. Informant (10) claimed that the salient point of having team work skills when it comes the Earth day program, "I have learned on how to work as a team even though we are not at the same team, what really matters is team work could make everything success". This indicates the matter of the struggles and hurdles they were facing during the program, with the spirit of team work they manage to make the event successful. Informant (12) also pointed out the important of teamwork, "The most important lesson that I have learned throughout his programme is cooperation between crew member is important. Without support from the crew member, this programme would be successful instead". Both informants agreed upon the role of teamwork will ensure the successful of the entire program.

In regards to cooperative skills, one informant (6) with her opinion stated that, "The important lesson is about "esprit de corps" among all members of team in order to ensure the successful of programme. "Esprit de corps" is used to express a sense of unity, common interest and purpose, as developed among associates in a task" which supported informant (10) who clearly stated that "Cooperation among us are important". Cooperative skills will ensure the program successful and this notion embark the overall teamwork skills and assist participant to understand each other. Without cooperation, the teamwork will face contradictions and arguments when the participant organizes program that contributes to pressure and stress environment. Cooperative will train participant to overcome loopholes of task and distribution of job that some of the informant might face difficulties to perform the job or require further training for specific task.

Meanwhile, positive attitudes such as patient and be responsible were developed throughout service-learning. One of the positive traits that should be trained in the $21^{\text {st }}$ century skills is how to 
INTERNATIONAL JOURNAL OF ACADEMIC RESEARCH IN BUSINESS AND SOCIAL SCIENCES Vol. 8, No. 12, Dec, 2018, E-ISSN: 2222-6990 @ 2018 HRMARS

be patient. The service-learning surpassed this traits as experience that driven from different environment and in this case referred to the client where the participant encountered during the earth day project. Two informants (2) and (3) shared similar beliefs about being a patient person, "The biggest thing I learned was the patience with children, not everything you taught they could understand since they are only 4-5 years old. I need to find a suitable method for them and "Be patient especially with kids..... Be empathetic....Control your emotions" when encountering unfavorable environment. Immersing with kids produced numerous perspectives in understanding their worldviews. It is meant to be a productive day to some participants of entertaining kids and at the same time create awareness of taking care of environment. In addition, participants manage to control their emotion and practice emphatical values.

Prospering inner values were some of the beneficial outcome projected from the earth day program. Participants were trained to be responsible of the decision being made through the service-learning project. One of the informants (12) admitted that, "I have learned to be more responsible towards my action, anything pertaining to decision making scenario was handle with full commitment and responsible". The observation took place on this matter, and participants had taken such a risky situation and one informant (10) reflected on this matter "The kids was aggressive. The parents are busy" portrayed the scenario that happened during the earth day program. However, one informant (4) agreed that with "Commitments. Responsible. Great participations. They become in one", flourishing the self-belief's they have had experienced after the program.

On the other hand, participants of the earth day project were involved in a decision making process either from the planning stage to the event day. Such situation involves critical and ad-hoc situations in ways the participants were asked to make outright decision with consensus of team members. One informant (10) embarked the salient result of quick decision making skills "Fast decision making is a good skill needed nowadays". She agreed that a good decision making skills is vital in the current settings. The ability to make a wise decision prosper participant maturity in handling such situations. Another issue pertaining to the earth day project was struggle in generating fund. One participant (4) encountered difficulty during asking for sponsorship, he stated, "my disappointment is when we can't get enough sponsorships although at first I've been told, we already have the sponsorships. I learn that, when we need to join others group, we need to prepare for any problems that might be happened". This situation empowered participants decision making skills as unexpected scenario might happen especially when it comes to fund and sponsorship opportunities. Participants decided upon the program to utilize recycle materials to make decoration and borrowed a mannequin for teaching and learning materials during the earth day. Indirectly, the cost of preparation was optimized to other important materials such as certificates and lunch pack for the kids.

Finally, the theme for the service-learning project was earth day and become the gist for the planned project. Participants were act as a role model for the kids to practice the positive attitudes towards care and preserve nature. Participant determined to do something about the flagrant issue pertaining to preserving the nature. He (7) enunciated, "we should practice the knowledge about preserving our nature rather just do awareness programme without further action. We should be the agent of 
change using all sources to spread awareness". The key word here is agent of change, depicting the proactive role of an individual to act upon something is not right in his mind. The service-learning project practiced positive self-esteem as they valued it very much throughout the program. The confidence of informant (3) was portrayed from his narrative, "self-esteem: the key to lifetime mental health and social happiness is building positive self-esteem". Participants experienced earth day project and begun to build self-beliefs and actively involved in the project. Immersing with the naturalistic settings of the earth day program prosper students awareness on preserving earth and did proctor alertly to the objective of the program.

\section{Discussions}

Service-learning has been applied in existing curriculum in many educational institutions because the nature of the service-learning program which is intentional, structured, and highly integrated efforts, primarily to integrate the curriculum from educational providers and employee requirements. The bilateral process of service-learning are robust and wide-spread of understanding the needs of community and also, train students to mix with myriad skills as to work with hands-on approaches. In addition to that service-learning has confirmed that with structural typed of service-learning project with clear objective offers strategic opportunities for students to think critically, plan, design, implement, and evaluate service activities that they believe will make a difference in their community (Chung \& McBride, 2015). These types of high quality service learning experiences may offer a critical enhancement of social and emotional skills for middle school students when paired with existing school curricula.

It is apparent from the findings that service-learning successfully developed traits of employability skills of students. Service-learning has more than a veneer of volunteering efforts, the prospect to develop $21^{\text {st }}$ century workforce skills was portrayed from the outcome of the earth day program. Students able to practice their different skills, interpersonal, and intrapersonal skills and myriad of other employability skills if other terms that familiar with the workforce environment. This platform can indicate that the students polish their innate skills and also learn new skills by integrating their personality together on top of existing theoretical knowledge. To accomplish this aim and to respond to a recent call for the $21^{\text {st }}$ century skills required skills by industries, the findings depicted emergence themes that relevant to current trends. A recent findings by Saavedra and Opfer (2012) suggested that the combination of life skills (agility, flexibility, and adaptability), workforce skills (collaboration, leadership initiative, and responsibility), applied skills (accessing and analyzing information, effective communication, and determining alternative solutions to problems), personal skills (curiosity, imagination, critical thinking, and problem solving), interpersonal skills (cooperation and teamwork), and noncognitive skills (managing feelings) corroborate with the outcome of the service-learning project. The compilation of above skills projected the accumulation of $21^{\text {st }}$ century skills occurred from the service-learning although it was discussed critically as the study was conducted.

Service-learning are deemed to be the alternative approach to enhance students maturity in critical thinking and be creative. The employment market requires graduates to think in a broad sense and be creative especially when it comes to economic recession. This includes to optimize the resources and manipulating existing company assets to increase profits and income generation. For example, 
students are requested to increase their ability to commensurate high-level thinking skills and communication complexity that includes understanding of intercultural skills. Griffin and Care (2016) suggested those wishing to be highly rewarded in the workforce of the future will need to be expert at interacting with people to acquire information, to understand what that information means, and to persuade others of its implications for action. The accumulation of effective communication will help graduates to market themselves in the global employment market and more likely get hired by the well-established and giant companies that operate around the globe. The employment will the capacity to communicate, collaborate and create. As the globalised world becomes more complex and integrated across national boundaries, individuals will need to be able to cross those boundaries to collaborate on shared information and emerging knowledge. The more complex the world becomes, the more individuals will need these skills (Griffin \& Care, 2014).

Participants have demonstrated their ability to immerse with the naturalistic settings of servicelearning. Hence, they depicted service-learning as successful event that assist them to understand community needs and build networking that is vital once they graduated from the program. For this reason, projecting the future workforce skills must be carried precociously as preparing students for future employment must be viewed through prediction and predictable measure. For example, Basten, Evers, Geijsel, and Vermeulen (2018) discuss the challenges and strategies to overcome the lack of skills of future workforce. They suggested in order to fulfil the demand for $21^{\text {st }}$ workforce skills in existing environment and foreseeable future are communication skills, social and cultural skills, creativity, critical thinking, problem solving, media wisdom, self-regulation, and collaboration. The findings also supported the findings from Van Laar, Van Deursen, Van Dijk, and De Haan (2017) stated that seven core skills: technical, information management, communication, collaboration, creativity, critical thinking and problem solving. Five contextual skills were also identified: ethical awareness, cultural awareness, flexibility, self-direction and lifelong learning.

The listed skills supporting the needs for the Industrial Revolution (RI) 4.0 brings a new dimension to the environment education in this country. Basically, this RI 4.0 is a transformation that complex towards global progress based on rapidly growing technology. In This flow of change changes people need to move along with this development so as not to miss out on applying technology in everyday life. Thus, the integration of RI 4.0 in everyday life should not be easy to follow technology development is in line with the current globalization trend today.

\section{Conclusion}

This article explores the outcome from service-learning project that comprises the theoretical learning from traditional classroom and transfer to community-typed activities. The practical approach of service-learning help students to practice their theoretical knowledge in real-life environment. Prospering the beneficial outcome from service-learning, this article also promotes the nurturing process of employability skills for graduate's employment. The rapid of trends in developing traits of employability skills has called upon the needs to study whether or not what learned from educational institutions can be transferred in employment settings. Because work environment is definitely beyond the life of educational journey, service-learning offer to synchronize the industrial 
expectations on university graduates by providing preliminary experience through community-typed activities. The transformative learning environment from university assist graduates to make quick adjustment to employment settings and this can be developed from service-learning experienced. Service-learning at the university have made splendid progress in constructing meaningful curriculum in educational institutions. Following a number of research attempts to embed service-learning to students' curriculum content, researchers preserved myriad context of service-learning and how service-learning can be understood as holistic approach towards knowledge creation, that means a collective of theoretical and practical approaches. Curriculum developer have to impose servicelearning rather volunteerism activities at the university level due to structural process of embedding learning content to practicalities. This approach assists students to hit the employment trends which is often desynchronized with what the university curriculum. Hence, curriculum must rapidly improve with the employment needs that cater local and global job perspectives. Therefore, the servicelearning serves as the solution as to communicate between the educational institutions and university when the discussion comes to what is best for graduate's employment profile.

\section{Acknowledgement}

The assistance and involvement of the Family, Adolescent and Child Research Centre of Excellence (FACE), and Faculty of Human Ecology, Universiti Putra Malaysia staffs are greatly appreciated.

\section{References}

Basten, F., Evers, A., Geijsel, F., \& Vermeulen, M. (2018). 21 $1^{\text {st }}$ century leadership skills for learning networks.

Berasategi, N., Alonso, I., \& Roman, G. (2016). Service-learning and higher education: evaluating students learning process form their own percpective. Procedia-Social and Behavioral Sciences, 228, 424-429.

Blueprint, M. E. (2016). Blueprint 2013-2025.(2013). Ministry of Education, Malaysia.

Billig, S. H., \& Waterman, A. S. (Eds.). (2014). Studying service-learning: Innovations in education research methodology. Routledge.

Chung, S., \& McBride, A. M. (2015). Social and emotional learning in middle school curricula: A service learning model based on positive youth development. Children and Youth Services Review, 53, 192-200.

Curtin, A. J., Martins, D. C., \& Schwartz-Barcott, D. (2015). A mixed methods evaluation of an international service learning program in the Dominican Republic. Public Health Nursing, 32(1), 58-67.

Dewey, J (1938). Experience and Education. New York: Collier.

Dienhart, C., Maruyama, G., Snyder, M., Furco, A., McKay, M. S., Hirt, L., \& Huesman, R. (2016). The impacts of mandatory service on students in service-learning classes. The Journal of social psychology, 156(3), 305-309.

Folgueiras Bertomeu, P., Luna González, E., \& Puig, G. (2013). Aprendizaje y servicio: estudio del grado de satisfacción de estudiantes universitarios. Revista de Educación, 2013, vol. 362, p. 159-185.

Flecky, K. \& Gitlow, L. (2011). Service Learning in Occupational Therapy Education. Massachusetts: Jones and Barlett Publishers 
INTERNATIONAL JOURNAL OF ACADEMIC RESEARCH IN BUSINESS AND SOCIAL SCIENCES

Vol. 8, No. 12, Dec, 2018, E-ISSN: 2222-6990 @ 2018 HRMARS

Foli, K. J., Braswell, M., Kirkpatrick, J., \& Lim, E. (2014). Development of leadership behaviours in undergraduate nursing students: A service-learning approach. Nursing education perspectives, 35(2), 76-82.

Furco, A. (1996). Service Learning: A balanced approach to experiential education. In Expanding Boundaries: Service and Learning. Washington: DC: Corporation for National and Community Service.

Furco, A. (2001). Advancing service-learning at research universities. New Directions for Higher Education, 2001(114), 67-78.

Furco, A., Jones-White, D., Huesman, R., \& Gorny, L. S. (2016). Modeling the influence of servicelearning on academic and sociocultural gains: Findings from a multi-institutional study. In Civic Engagement and Community Service at Research Universities (pp. 143-163). Palgrave Macmillan, London.

Gezuraga Amundarain, Monike, \& Malik Liévano, Beatriz. (2015). Orientación y acción tutorial en la universidad: Aportes desde el aprendizaje-servicio. Revista Española De Orientación $Y$ Psicopedagogía, 26 (2), 8-25.

Giles, D. E., \& Eyler, J. (1994). The theoretical roots of service-learning in John Dewey: Toward a theory of service-learning. Michigan Journal of Community Service Learning, 1(1), 77-85).

Griffin, P., \& Care, E. (Eds.). (2014). Assessment and teaching of 21st century skills: Methods and approach. Springer.

Henderson, K. (1984). Volunteerism as Leisure. Journal of Voluntary Action Research, 13(1), 55-63.

Howard, J. (2014). Service-learning research: Foundational issues. In Studying Service-Learning (pp. 15-26). Routledge.

Howard, J. \& Jacoby, B. (Ed.) (2015). Service-Learning Essentials: Questions, Answers, and Lessons Learned. San Francisco, CA: Jossey Bass.

Huda, M., Jasmi, K. A., Alas, Y., Qodriah, S. L., Dacholfany, M. I., \& Jamsari, E. A. (2018). Empowering Civic Responsibility: Insights from Service Learning. In Engaged Scholarship and Civic Responsibility in Higher Education (pp. 144-165). IGI Global.

Jacoby, B. (Ed.) (1996b). Securing the future of service-learning. Service-Learning in Higher Education: Concept and Practices. San Francisco, CA: Jossey Bass.

Kohlbry, P. W. (2016). The impact of international service-learning on nursing students' cultural competency. Journal of Nursing Scholarship, 48(3), 303-311.

Kolb, D. (1984). Experiential Learning: Experience as the Source of Learning and Development. Englewood Cliffs, NJ: Prentice Hall.

Kuh, G. D. (2008). Excerpt from high-impact educational practices: What they are, who has access to them, and why they matter. Association of American Colleges and Universities.

McDonald, J., \& Dominguez, L. A. (2015). Developing university and community partnerships: A critical piece of successful service learning. Journal of College Science Teaching, 44(3).

Richard, D., Keen, C., Hatcher, J. A., \& Pease, H. A. (2017). Pathways to adult civic engagement: Benefits of reflection and dialogue across difference in higher education service-learning programs. Michigan Journal of Community Service Learning, 23(1).

Porter, L. R. (1997). Creating the virtual classroom: Distance learning with the Internet. John Wiley \& Sons, Inc.. 
INTERNATIONAL JOURNAL OF ACADEMIC RESEARCH IN BUSINESS AND SOCIAL SCIENCES

Vol. 8, No. 12, Dec, 2018, E-ISSN: 2222-6990 C 2018 HRMARS

Saavedra, A. R., \& Opfer, V. D. (2012). Learning 21st-century skills requires 21st-century teaching. Phi Delta Kappan, 94(2), 8-13.

Shumer, R. D. (2014). Learning from qualitative research. In Service-learning (pp. 41-54). Routledge.

Smiley, C., Rogers, George E., Kelley, Todd, \& Oakes, William (2012). Incorporating Service-learning within Engineering and Technology Education in Secondary Schools, ProQuest Dissertations and Theses.

Sun, Y. C., \& Yang, F. Y. (2015). I help, therefore, I learn: service learning on Web 2.0 in an EFL speaking class. Computer Assisted Language Learning, 28(3), 202-219.

Van Laar, E., van Deursen, A. J., van Dijk, J. A., \& de Haan, J. (2017). The relation between 21st-century skills and digital skills: A systematic literature review. Computers in human behavior, 72, 577588.

Waterman, A. S. (2014). An overview of service-learning and the role of research and evaluation in service-learning programs. In Service-learning (pp. 15-26). Routledge.

Zins, J. E., Bloodworth, M. R., Weissberg, R. P., \& Walberg, H. J. (2007). The scientific base linking social and emotional learning to school success. Journal of educational and psychological consultation, 17(2-3), 191-210. 